\title{
Thermographic monitoring of asphalt concrete surface with phase change materials inclusions for icing delays purposes
}

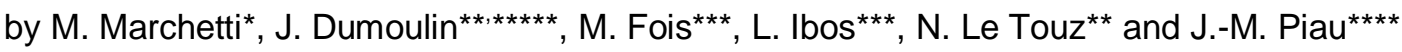 \\ *Cerema - Direction Territoriale Est - Laboratoire Régional de Nancy, 71 rue de la Grande haie, F-54510 \\ Tomblaine, France, mario.marchetti@cerema.fr \\ **UUNAM Université, IFSTTAR, COSYS, F-44340, Bouguenais, France, jean.dumoulin@ifsttar.fr \\ ***Université Paris-Est, CERTES, 61 avenue du Général De Gaulle, 94010 Créteil, France, ibos@u-pec.fr \\ ****UNAM Université, IFSTTAR, MAST, F-44340, Bouguenais, France, jean-michel.piau@ifsttar.fr \\ *****INRIA/IRISA, I4S Team, Campus de Beaulieu, 35042 Rennes, France
}

\begin{abstract}
Arial, 9pt, bold)
If de-icers still are the main solution to avoid black ice occurrence and snow accumulation on pavements, some alternatives based on transportation infrastructure modifications have been tested over the past years. They aim at the reduction of environmental impacts and at coping with budgets constraints and cuts, including in winter maintenance. Among existing ones, the implementation of phase changes materials (PCM) into the infrastructure was evaluated to delay the occurrence of water in its solid phase on the surface. Additional results were obtained with an asphalt concrete in simulated winter conditions, indicating a tenuous thermal effect at the surface.
\end{abstract}

\section{Introduction}

The mobility in adverse weather conditions during winter time relies on many factors, from the ability of winter services to cope with the meteorological phenomenon to the nature of the infrastructure submitted to this event. Despites years of efforts in terms of staff training, evaluations on economical costs [1] of winter maintenance, on its environmental impacts, the improvements in weather forecast through numerical models [2-5], hundreds of tons of de-icers are still spread over pavements surfaces. One last mean to influence this de-icer trend is to implement a change in the infrastructure itself to avoid black ice occurrence and snow accumulation over the surface submitted to traffic. Such solution has nevertheless to be compliant with maintenance and repairs works on pavements, and is in full opposition and contrast with such changes as ones made on Serso Bridge (Switzerland) for instance. Previous works consisted in evaluation the performance of a multi-layered asphalt concrete structure with a fluid circulating a porous layer, and of phase change materials (PCM) embedded into concrete [6]. Additional tests were then conducted considering another phase change material [7] with the appropriate thermodynamic characteristics in the form of inclusions into asphalt concrete, and submitted to controlled winter conditions during several days. The purpose of these PCM was to maintain a stable temperature at the surface for a given duration to ensure the melting of solid water. Results indicated a tenuous effect at the pavement surface, and temperature variations not systematically observed at expected phase transition temperature.

\section{Experimental settings and materials}

\subsection{Simulated winter conditions and temperature monitoring}

Atmospheric conditions representative of winter were simulated in a several cubic meters large climatic chamber. Imposed cyclic air temperature variations are as follows: start at $10^{\circ} \mathrm{C}$, with over $12 \mathrm{~h}$ at this temperature to reach a thermal homogeneity, cooling down to $-5^{\circ} \mathrm{C}$ in several steps, finally back to initial temperature. Air temperature was measured with a Pt100 probe. Surface temperature was monitored by thermocouples and a FLIR A655c infrared camera recording images every 10s. The infrared scene included a mirror for further radiative corrections on thermal images, along with surface painted with Nextel 811-21, which emissivity is supposed constant in the selected temperature range.

\subsection{Asphalt concrete samples and PCM}

Four asphalt concrete samples were $50 \mathrm{~cm} \times 18 \mathrm{~cm} \times 14 \mathrm{~cm}$ parallelepipeds, manufactured with materials conventionally used in roads. One did not contain any PCM inclusions, while three other ones respectively contained one and two inclusions at depths ranging from $20 \mathrm{~mm}$ and as down as $45 \mathrm{~mm}$ below the surface. They were installed in the floor of the climatic chamber on a polystyrene foam used as thermal insulator, and their sides were also insulated with polystyrene. 


\subsection{1/qirt.2016.078}

Selected PCM was formic acid, either in its pure form or diluted into water $(20 \% \mathrm{v} / \mathrm{v}$ water $-80 \% \mathrm{v} / \mathrm{v}$ formic acid, $30 \%-70 \%$, and $40 \%-60 \%$ ). In the literature, the liquid to solid temperature transition is given at $7.8^{\circ} \mathrm{C}$. The liquid was placed into metallic containers then inserted into the asphalt concrete sample. Thermocouples were attached to these containers, either on the upper lid or at their bottom.

\section{Results and analysis}

Temperature profiles from the thermocouples attached to the surface and the PCM containers did indicate variation consistent with the ones of air. There were no indication of stable temperature due to the phase transition of the PCM (figure 1a). When considering thermal images, a temperature variation was monitored during the temperature increase, between $-5^{\circ} \mathrm{C}$ and $2^{\circ} \mathrm{C}$ (figures $1 \mathrm{~b}, 1 \mathrm{c}$ ). This effect is quite tenuous, and it is difficult to link the temperature at which it was observed to a potential phase transition. This raises the question of a supercooling occurrence, but also the possibility of molecular organization either of formic acid in its dimer form [8], consequently modifying the phase transition temperature.

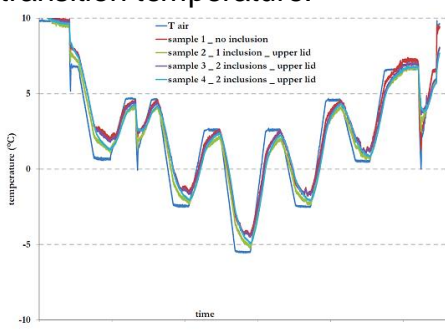

(a)

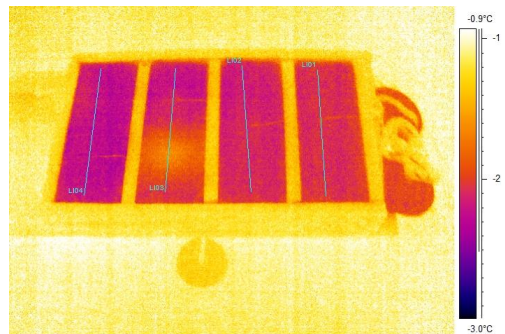

(b)

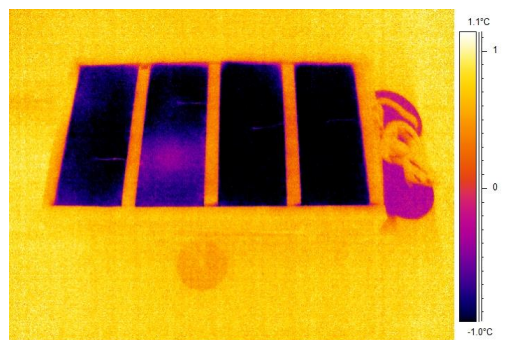

(c)

Fig. 1. Air temperature variations in a climatic chamber (a), PCM inclusions (b) in asphalt concrete samples (c)

\section{Conclusion}

The possibility to rely on PCM to maintain a positive stable temperature at the surface of asphalt concrete was investigated. It consisted in inclusions of acid formic in pavement samples. Temperatures was monitored by both thermocouples and an infrared camera. Results indicated a tenuous thermal effect at the surface when samples were submitted to a cyclic air temperature variations, raising supercooling questions and possible dimer clusters into the PCM in its liquid phase, affecting the transition temperature.

\section{REFERENCES}

[1] Petty, K. R., Mahoney, W. P., The U.S. Federal Highway Administration winter road Maintenance Decision Support System (MDSS): Recent enhancements and refinements. Proceedings of the 14th Standing International Road Weather Conference, Standing International Road Weather Commission, Prague, Czech Republic, 14-16 May, 2008.

[2] Bouilloud, L., Martin, E., A coupled model to simulate snow behavior on roads. J. Appl. Meteorol. Clim., 45, 500516, 2006.

[3] Hammond, D.S., The validation and improvement of route-based road weather forecasts. PhD Thesis, School of Geography, Earth and Environmental Sciences, The University of Birmongham, U.K., 2011.

[4] Khalifa A., Marchetti M., Buès M., Appreciation of the traffic effects on the RST by infrared thermography. SPIE Optics+Photonics International Conference, San Diego (California, USA), 17-21 august 2014.

[5] Marchetti M., Khalifa A., Bues M., Methodology to forecast road surface temperature with Principal Components Analysis and Partial Least-Square regression. Application to a urban configuration. Advances in Meteorology, 2015.

[6] Marchetti M., Dumoulin J., Le Touz N., Moutton M., Ludwig L., Gabet T., Piau J-M., Ibos L., Infrared thermography applied to surface temperature survey of enhanced pavement sample addressing self-de-icing functionality. QIRT-Asia Conference on quantitative infrared thermography, Mamallapuram (Inde), 6-10 juillet 2015.

[7] Cabeza L.F., Castell A., Barreneche C., de Gracia A., Fernández A.I., Materials used as PCM in thermal energy storage in buildings: A review. Renewable and Sustainable Energy Reviews, Volume 15, Issue 3, April 2011, 1675-1695

[8] Fathi S., Gonzalez M. A., Bahri M., Nasr S., Bellissent-Funel M.-C., Structural investigation of liquid formic acid by $\mathrm{X}$-ray and neutron scattering, ab initio calculations and molecular dynamics simulations. Journal of Molecular Liquids, Volume 207, July 2015, Pages 125-135 